\title{
Pemberdayaan Usaha Ekonomi Produktif bagi Masyarakat di Kelurahan Allepolea, Kecamatan Lau Kabupaten Maros
}

\section{Ikhwan Maulana Haeruddin ${ }^{1 *}$ Abdul Hakim ${ }^{2}$, Muhammad Ichwan Musa ${ }^{1}$, Agung Widhi Kurniawan', Abdi Akbar ${ }^{1}$, Uhud Darmawan Natsir ${ }^{1}$, \& M. Ilham Wardhana Haeruddin ${ }^{1}$ \\ ${ }^{1}$ Program Studi Manajemen, Fakultas Ekonomi Universitas Negeri Makassar, Indonesia, 90222}

${ }^{2}$ Program Studi Ekonomi Pembangunan, Fakultas Ekonomi Universitas Negeri Makassar, Indonesia, 90222

E-mail: ikhwan.maulana@unm.ac.id

DOI: https://doi.org/10.37339/jurpikat.v1i2.331

\section{Info Artikel: \\ Diterima : \\ 2020-10-17 \\ Diperbaiki : \\ 2020-10-24 \\ Disetujui : \\ 2020-10-26}

Kata kunci: Pemberdayaan

Usaha Ekonomi, Skala

Kelurahan, Peningkatan Nilai

Produk
Abstract: Kegiatan ini bertujuan untuk memberikan penyuluhan dan pelatihan tentang kewirausahaan dan pengolahan luaran yang menghasilkan produk bernilai ekonomis yaitu sabun dan deterjen, serta mengetahui metode pemasarannya. Sasaran peserta dari kegiatan ini adalah warga kelurahan Allepolea Kecamatan Lau di Kabupaten Maros. Secara umum, peserta sangat antusias mengikuti pelatihan yang ditunjukkan dari ketekunan dan kedisiplinan dalam mengikuti setiap tahapan dalam kegiatan. Selain itu setiap peserta ikut berpartisipasi dalam menentukan materi pelatihan terkait dengan pelaksanaan tugas yang dijalankan sehari-hari. Setiap peserta mampu menghasilkan produk bernilai ekonomis dan juga mampu memasarkan produk tersebut baik melalui mekanisme penjualan offline maupun online. Melalui kegiatan ini setiap peserta merasakan manfaat dari kegiatan pemberdayaan usaha ekonomi produktif melalui kegiatan dan mengharapkan kegiatan seperti ini dapat diberikan secara rutin dan juga membawa khazanah baru bagi pengetahuan dan keterampilan mereka sehingga akan meningkatkan taraf kehidupan warga secara ekonomi. 
Keywords: Empowerment of economic enterprises, village scale, increase product value
Abstract: This activity aims to provide counseling and training on entrepreneurship and processing output that produces economically valuable products, namely soap and detergents, as well as knowing the marketing methods. The target participants of this activity are residents of the Allepolea sub-district, Lau District in Maros Regency. In general, participants were very enthusiastic about participating in the training which was shown by their persistence and discipline in following each stage of the activity. In addition, each participant participates in determining training materials related to the implementation of daily tasks. Each participant is able to produce products of economic value and is also able to market these products both through offline and online sales mechanisms. Through this activity each participant feels the benefits of empowering productive economic enterprises through activities and hopes that activities like this can be provided regularly and also bring new treasures to their knowledge and skills so that it will improve the lives of citizens economically.

\section{Pendahuluan}

Pemberdayaan merupakan suatu konsep untuk memberikan tanggungjawab yang lebih besar kepada orang-orang tentang bagaimana melakukan pekerjaan (Haeruddin, Musa, \& Musa, 2017). Pemberdayaan akan berhasil jika dilakukan oleh pemangku kepentingan (stakeholders) yang dilakukan secara terstruktur dengan membangun budaya kerja yang baik. Konsep pemberdayaan terkait dengan pengertian pembangunan masyatakat dan pembangunan yang bertumpu pada masyarakat. Program-program pemberdayaan sumberdaya manusia telah dilakukan pemerintah (Buvinić dan Furst-Nichols. 2016). Hal ini sejalan dengan tujuan pembangunan Indonesia yaitu membangun manusia Indonesia seutuhnya, maka pembangunan harus merupakan perubahan sosial yang tidak hanya terjadi pada taraf kehidupan masyarakat belaka tetapi juga pada peranan unsur-unsur di dalamnya (Haeruddin, Musa, \& Musa, 2017). Pemberdayaan masyarakat dalam penanggulangan kemiskinan menjadi komitmen bersama antara pemerintah pusat dengan pemerintah daerah (Septiyana, Nizaruddin, Rahmawati, Atma, Putri, \& Astuti, 2020).

Oleh karena itu, kemiskinan terutama yang diderita oleh kaum miskin merupakan masalah utama berskala nasional yang penanggulanggannya tidak dapat 
ditunda lagi dan harus menjadi prioritas utama dalam pelaksanaan pembangunan kesejahteraan sosial (Sadji, 2004). Tawaran kredit UMKM dari pengusaha dan perbankan sulit diakses oleh kaum miskin, karena keterbatasan kemampuan dan asset yang dimiliki. Pemerintah dalam hal ini Dinas Sosial berusaha menemukan pola yang efektif agar kaum miskin dapat memperoleh akses modal usaha tanpa agunan dengan tetap mendorong tanggungjawab bersama melalui pola terpadu Kelompok Usaha Bersama (KUBE) dan Lembaga Keuangan Mikro (LKM) (Sadji, 2004).

Kabupaten Maros terdiri dari 14 kecamatan dengan luas wilayah 1.619,12 km2 yang terdiri atas 103 kelurahan, 80 Desa (Utari \& Riani, 2015). Berdasarkan data dari BPS Kabupaten Maros, peranan masing-masing kecamatan dalam menciptakan nilai tambah ekonomi cukup bervariasi. Kecamatan Simbang, Mandai, dan Maros Baru adalah salah satu dari Kecamatan yang memiliki kontribusi positif yang signifikan terhadap pertumbuhan ekonomi Kabupaten Maros (Balai Pusat Statistik, 2018). Di sisi lain, Kecamatan Lau dan Kecamatan Turikale, memiliki kontribusi di bawah rata-rata sebesar 8\%, di mana Kecamatan Lau mempunyai peran terkecil, yaitu 4, 52\%.

Alfian, Tan dan Soemardjan (1980) mengatakan ada dua kategori pengukuran tingkat kemiskinan yaitu kemiskinan absolut dan kemiskinan relatif. Kemiskinan absout merupakan suatu kondisi di mana tingkat pendapatan seseorang tidak cukup untuk memenuhi kebutuhan pokok seperti pangan, sandang, papan, kesehatan dan pendidikan. Sedangkan kemiskinan relatif adalah penghitungan kemiskinan berdasarkan proporsi distribusi pendapatan dalam suatu daerah. Kemiskinan ini dikatakan relatif karena lebih berkaitan dengan distribusi pendapatan lapisan sosial. Bank Dunia menetapkan kriteria minimum kemiskinan sebesar \$US 50 per kapita/tahun. Pengembangan Usaha Ekonomi Produktif (UEP) dan Usaha Kesejahteraan Sosial (UKS) melalui Kelompok Usaha Bersama (KUBE) bagi kaum miskin merupakan salah satu program yang dikembangkan pemerintah melalui Dinas Sosial. Salah satu tujuan khusus diadakannya kegiatan ini adalah bagaimana memberdayakan perempuan di daerah pedesaan yang selama ini termarjinalkan agar dapat lebih produktif dan secara tidak langsung dapat berkontribusi kepada pembangunan nasional (Blumber, 2005).

\section{Identifikasi Permasalahan yang Dihadapi Mitra}

Berdasarkan analisis situasi yang telah dikemukakan di atas, maka permasalahan yang hadir di lingkungan Kelurahan Kecamatan Lau antara lain adalah jumlah masyarakat miskin yang cenderung meningkat, peluang usaha yang ada 
relatif terbatas, belum optimalnya usaha ekonomi produktif, dan keterbatasan akses pasar bagi kelompok usaha

\section{Subjek kegiatan}

Kabupaten Maros terdiri dari 14 kecamatan dengan luas wilayah 199,26 km² yang terdiri atas 103 kelurahan, dan 80 Desa (Utari \& Riani, 2015). Berdasarkan data dari BPS Kabupaten Maros, peranan masing-masing kecamatan dalam menciptakan nilai tambah ekonomi cukup bervariasi. Kecamatan Simbang, Mandai, dan Maros Baru adalah salah satu dari Kecamatan yang memiliki kontribusi positif yang signifikan terhadap pertumbuhan ekonomi Kabupaten Maros (Balai Pusat Statistik, 2018). Di sisi lain, Kecamatan Lau dan Kecamatan Turikale, memiliki kontribusi di bawah rata-rata sebesar 3\%, di mana Kecamatan Lau mempunyai peran terkecil, yaitu $2,52 \%$.

\section{Metode}

Berdasarkan tema kegiatan pengabdian pada masyarakat yaitu pemberdayaan masyarakat di dalam menciptakan usaha ekonomi produktif pada warga Kelurahan Lau, maka metode yang ditawarkan sebagai berikut:

- Memberikan pemahaman pada mitra tentang usaha ekonomi produktif dan mempraktikkan ilmu yang didapatkan. Pada sesi ini, pemateri menanamkan pemahaman ke warga tentang konsep Dasar usaha ekonomi produktif dan juga bagaimana cara memulai usaha tersebut. Kemudian dilanjutkan dengan sesi pelatihan yang menitikberatkan pada kemampuan melaksanakan kegiatan tentang (1) mengidentifikasi, memilih dan merumuskan usaha yang ingin dijalankan, (2) menyusun studi kelayakan usaha, (3) mengumpulkan bahanbahan dan sumber daya yang dimiliki, (4) menjalankan usaha secara teknis. Pemberian kemampuan ini dilakukan dengan teknik simulasi agar para warga mendapatkan pengalaman langsung sekaligus pengayaan dari temantemannya dan tim pelatih (Mengstie dan Singh, 2020).

- Memberikan motivasi pada para warga tentang potensi dan prospek usaha ekonomi kreatif yang dapat membantu menyelesaikan masalah. Pemateri memberi penjelasan tentang konsep usaha produktif, sesi pelatihan ini menitikberatkan pada pemberian penjelasan mengenai memotivasi agar warga mau memahami dan segera memulai usaha ekonomi produktif (Lahafi dkk, 2019). 
Secara teknis, metode dalam kegiatan ini dapat dibagi menjadi:

- Penyuluhan.

Materi penyuluhan adalah wirausaha dan peluang usaha rumahan, prinsip dasar produksi, pengemasan dan pemasaran produk. Tujuan penyuluhan ini adalah memberikan ilmu dan wawasan baru kepada ibu-ibu di Kelurahan Lau tentang wirausaha dan peluang usaha berbasis rumahan, sehingga terbuka pikiran serta tumbuh minat dan motivasi dalam diri mereka untuk berwirausaha. Di samping itu juga diberikan materi tentang prinsip dasar pembuatan, pengemasan dan pemasaran produk, bertujuan agar mitra mengetahui cara pembuatan, pengemasan yang baik dan strategi pemasaran produk. Penyuluhan ini disampaikan dalam bentuk ceramah dan tanya jawab kepada peserta.

- Pelatihan

Salah satu materi pelatihan adalah bagaimana cara pembuatan sabun (sabun mandi, sabun cuci piring, pewangi pakaian) dan deterjen. Kegiatan ini bertujuan untuk memberikan keterampilan tentang cara produksi, pengemasan dan pemasaran produk. Pelatihan tersebut disampaikan dalam bentuk ceramah yang dilanjutkan dengan eksperimen langsung dan tanya jawab tentang cara pembuatan dan pengemasan aneka produk tersebut. Pelatihan dilaksanakan sampai semua peserta mahir mempraktekkan sendiri.

- Prosedur kegiatan

Kegiatan pengabdian ini meliputi: 1) Koordinasi dengan mitra, terkait dengan penyusunan jadwal kegiatan; 2) Persiapan penyuluhan dan pelatihan; 3) Penyuluhan tentang wirausaha dan peluang usaha rumahan; 4) Penyuluhan tentang prinsip dasar pembuatan sabun cair (sabun mandi, sabun cuci piring, pewangi pakaian), dan deterjen; 5) Penyuluhan tentang pengemasan dan pemasaran produk; 6) Pelatihan cara pembuatan sabun cair (sabun mandi, sabun cuci piring, pewangi pakaian), dan deterjen; 7) Pelatihan tentang pengemasan dan pemasaran produk; dan 8) Evaluasi dan feedback (dapat dilihat pada Gambar 1).

- Partisipasi Mitra

Partisipasi mitra dalam pelaksanaan kegiatan ini adalah partisipasi aktif, dari mulai perencanaan kegiatan, penyusunan jadwal penyuluhan dan pelatihan. 
Partisipasi mitra akan dievaluasi. Evaluasi akan dilaksanakan selama dan setelah pelaksanaan kegiatan penyuluhan dan pelatihan. Selama pelaksanaan kegiatan dilakukan evaluasi dengan metode pengamatan langsung oleh Tim Pengabdian. Sedangkan setelah pelaksanaan kegiatan dilakukan evaluasi dengan metode pengamatan terhadap hasil kegiatan dan metode angket. Kriteria evaluasi meliputi kesadaran dan antusiasme peserta penyuluhan dan pelatihan dalam mengikuti kegiatan serta tingkat kemahiran peserta dalam mempraktekkan sendiri sabun cair (sabun mandi, sabun cuci piring, pewangi pakaian), dan deterjen yang telah diajarkan. Pelatihan yang akan dilaksanakan dapat terlaksana dengan baik jika ada kerjasama yang baik antara tim pelaksana dengan mitra yakni para warga Kelurahan Lau di Kabupaten Maros. Partisipasi mitra dalam hal ini yaitu mulai dari mengkoordinir para ibu-ibu yang akan ikut serta dalam pelatihan, membantu menyediakan fasilitas ruangan sebagai tempat pelatihan dan menyediakan perangkat yang akan digunakan seperti $L C D$, sound system, laptop, komputer, alat tulis menulis dan sebagainya.

Diagram alur pelaksanaan kegiatan disajikan pada Gambar 1.
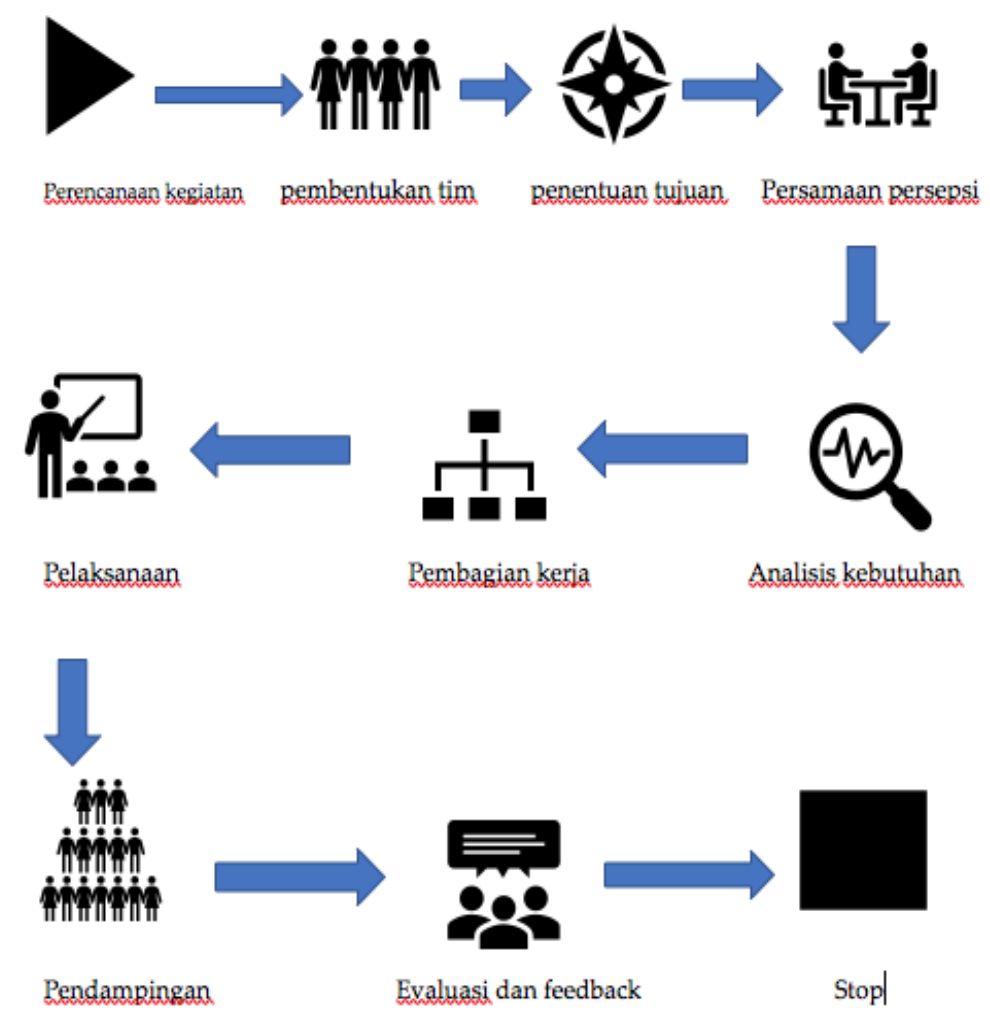

Gambar 1. Diagram alur pelaksanaan kegiatan 


\section{Hasil dan Pembahasan}

Persiapan kegiatan ini berupa penentuan formula sabun dan deterjen, pembuatan modul penyuluhan dan pelatihan. Modul penyuluhan berisi materi dasar tentang wirausaha dan peluang usaha rumahan, prinsip dasar pembuatan produk, pengemasan dan pemasaran produk. Produk berupa deterjen, sabun cuci tangan, sabun cuci piring serta pelembut dan pewangi pakaian. Modul pelatihan berisi tentang bahan-bahan, alat-alat dan cara pembuatan deterjen, sabun cuci tangan, sabun cuci piring serta pelembut dan pewangi pakaian. Pada persiapan pelatihan, Tim pengabdian melakukan uji coba resep pembuatan produk sabun dan deterjen, sehingga didapatkan komposisi yang tepat dan memberikan hasil optimal.

Alat dan bahan yang dibutuhkan pada pelatihan pembuatan deterjen, sabun cuci tangan, sabun cuci piring serta pelembut dan pewangi pakaian, antara lain baskom kecil, pengaduk kayu, sendok, gelas ukur, masker, sarung tangan, kain lap, timbangan, wadah plastik kecil, wadah plastik besar, ayakan, corong, botol plastik, plastik kemasan, sealer plastik, label.

\section{Pelaksanaan Pelatihan}

Pelatihan diberikan dalam bentuk ceramah yang dilanjutkan dengan eksperimen langsung dan tanya jawab (Sugiyono, 2006; Miles \& Huberman, 1994). Materi yang disampaikan adalah wirausaha dan peluang usaha rumahan, prinsip dasar pembuatan produk, pengemasan dan pemasaran produk, khususnya produk sabun dan deterjen. Praktek cara pembuatan pembuatan deterjen, sabun cuci tangan, sabun cuci piring serta pelembut dan pewangi pakaian. Warga dibagi ke dalam beberapa kelompok, kemudian dengan dibimbing Tim pengabdian mempraktekkan sendiri pembuatan produk tersebut yang disajikan pada Gambar 2.

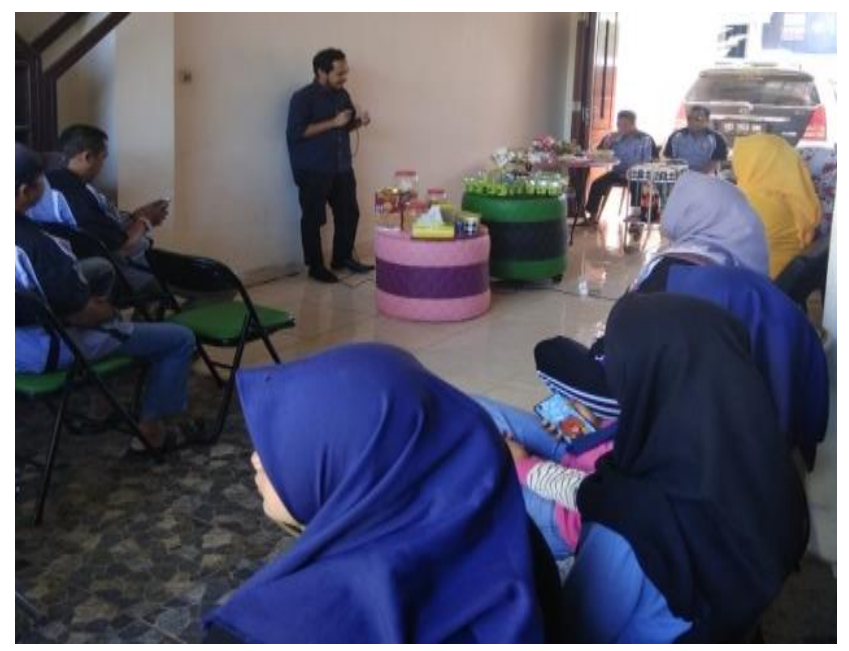

Gambar 2. Pelaksanaan pelatihan 


\section{Evaluasi dan Tindak Lanjut}

Evaluasi kegiatan dilakukan dengan memberikan angket kepada seluruh warga untuk melihat sejauh mana tanggapan peserta terhadap kegiatan yang telah dilakukan. Aspek yang ditinjau adalah tentang pendapat dan tanggapan peserta tentang pelaksanaan pelatihan pembuatan sabun dan deterjen (Kabeer. 2012). Hasil angket memperlihatkan bahwa mitra sangat setuju dengan kegiatan pengabdian ini karena mitra belum pernah mendapatkan penyuluhan dan pelatihan tentang peluang usaha rumahan berupa sabun dan deterjen. Di samping itu peserta juga termotivasi dan tertarik untuk mengembangkan lebih lanjut sehingga dapat berwirausaha mandiri sehingga secara agregat akan menjadi keunggulan bersaing dari daerah kelurahan jika dibandingkan dengan kelurahan lainnya (Saksono, 2012). Tindak lanjut dari kegiatan ini adalah dengan respon positif dari Kepala Kelurahan yang akan membentuk KUBE di lingkungan Kelurahannya. Selanjutnya, pelatihan berikutnya akan diarahkan kepada pemberdayaan platform digital sebagai media promosi dan penjualan. Ini sangat penting mengingat masifnya penggunaan gawai di semua kalangan, sehingga saluran distribusi dan komunikasi pemasaran akan lebih efektif (Febriyantoro \& Arisandi, 2018). Kepala Kelurahan juga akan menampung semua produk sabun dan deterjen yang dihasilkan oleh warganya untuk dijual ke kelurahan lain. Kegiatan diakhiri dengan foto bersama, yang mana semua foto-foto telah disetujui oleh warga melalui consent form yang ditandatangani untuk dapat dipublikasikan. Foto bersama disajikan pada Gambar 3.

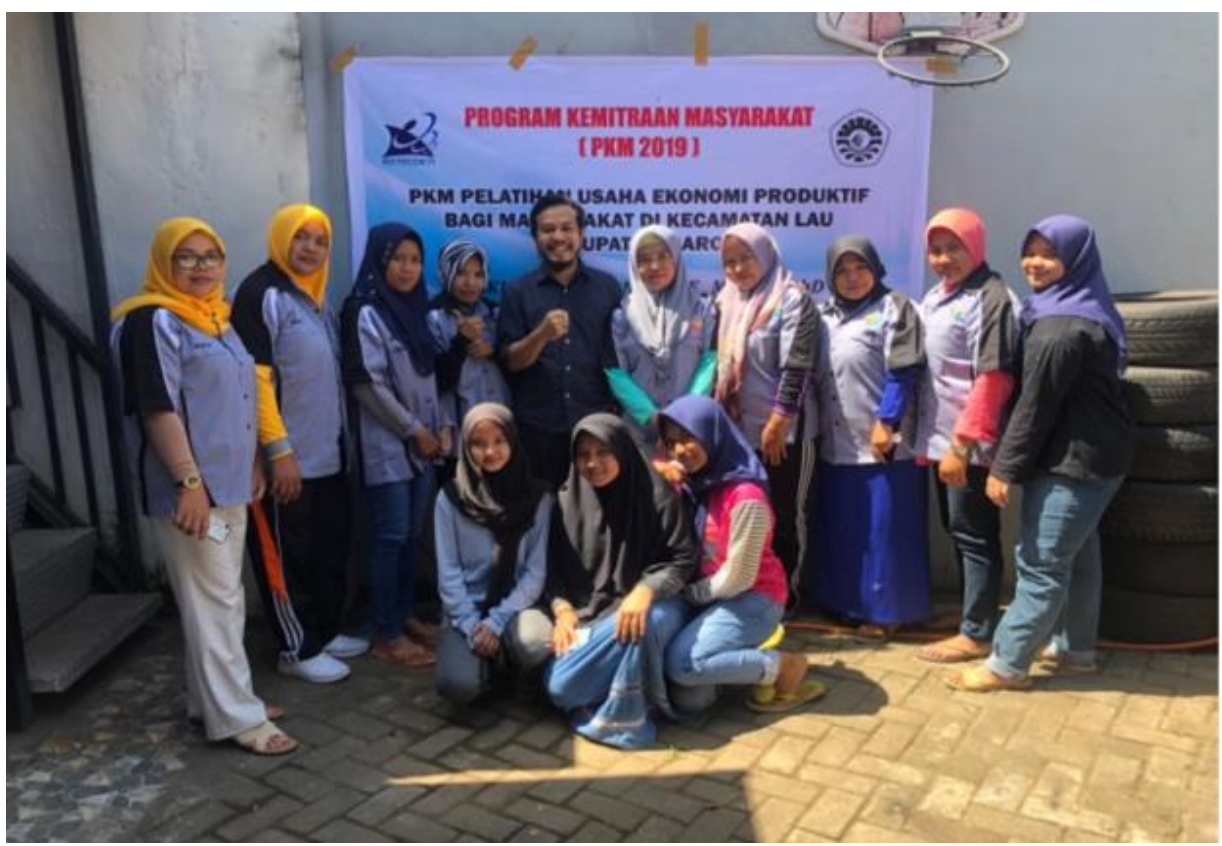

Gambar 3. Foto bersama 
Kegiatan produktif ini selain dapat meningkatkan taraf kehidupan warga, di sisi lain juga dapat mengurangi tingkat depresi dan Kekerasan di Dalam Rumah Tangga (KDRT) (Gibbs dkk, 2020). Ini diakui oleh sebagian warga yang selama ini mengalami perlakuan tersebut. Setelah mendapatkan keterampilan, potensi stress mereka dapat tersalurkan melalui hal yang positif dan juga KDRT yang biasanya dipicu oleh motif ekonomi kini bisa teratasi. Pemanfaatan ICT bagi warga khususnya warga perempuan kini dapat lebih maksimal di dalam mempromosikan dan mendistribusikan produk luaran dari kegiatan pelatihan ini (Jorge, 2002).

\section{Kesimpulan}

Berdasarkan hasil kegiatan pelatihan, maka dapat dikemukakan beberapa kesimpulan sebagai berikut:

1. Keterampilan dalam pemberdayaan usaha ekonomi produktif sangat bermanfaat bagi warga dan juga mitra di Kelurahan Allepolea Kecamatan Lau di Kabupaten Maros khususnya dapat menambah pengetahuan dan keterampilan tentang berwirausaha dalam hal menciptakan produk dan juga mengetahui Metode pemasaran sehingga taraf hidup warga dapat meningkat. Ini dapat diketahui dengan adanya testimoni dari warga yang menyatakan adanya peningkatan pendapatan secara ekonomi berasal dari keterampilan yang didapatkan dari pelatihan ini.

2. Umumnya peserta menganggap bahwa kegiatan ini sangat bermanfaat untuk membangun kemampuan dan keterampilan di dalam berwirausaha dan menyarankan agar pelatihan seperti ini rutin dilakukan agar warga tidak hanya memiliki keterampilan dalam hal membuat sabun dan deterjen tetapi juga memiliki keterampilan di dalam membuat produk atau jasa lainnya. Per Juli tahun 2020, produk yang dihasilkan masih terpusat pada produk sabun dan deterjen. Ini disebabkan karena pengetahuan warga terhadap produksi produk lain masih terbatas dan masih memerlukan pendampingan.

\section{Ucapan Terima Kasih}

Terimakasih kepada pihak Universitas Negeri Makassar atas pelaksanaan Program Kemitraan Masyarakat (PKM), Terimakasih kepada Pihak warga masyarakat dan pemerintah di Kecamatan Lau dan Kelurahan Allopolea, Kabupaten Maros, Sulawesi Selatan. Juga tak lupa ucapan terima kasih kepada Tim Pengabdi Fakultas Ekonomi Universitas Negeri Makassar. 


\section{Referensi}

Alfian, M. G. Tan dan Selo Soemardjan (eds.), 1980. Kemiskinan Struktural; Suatu Bunga Rampai.

Blumberg, R. L. (2005, August). Women's economic empowerment as the "magic potion" of development. In 100th Annual Meeting of the American Sociological Association, August, Philadelphia.

Buvinić, M., \& Furst-Nichols, R. (2016). Promoting women's economic empowerment: what works?. The World Bank Research Observer, 31(1), 59-101.

Febriyantoro, M. T., \& Arisandi, D. (2018). Pemanfaatan digital marketing bagi usaha mikro, kecil dan menengah pada era masyarakat ekonomi ASEAN. Jurnal Riset Manajemen dan Bisnis Dewantara (JMD), 1(2), 61-76.

Gibbs, A., Corboz, J., Chirwa, E., Mann, C., Karim, F., Shafiq, M., Mecagni, A., Maxwell-Jones, \& Jewkes, R. (2020). The impacts of combined social and economic empowerment training on intimate partner violence, depression, gender norms and livelihoods among women: an individually randomised controlled trial and qualitative study in Afghanistan. BMJ global health, 5(3), e001946.

Haeruddin, M. I. M., Musa, M. I., \& Musa, C. I. (2017). Pelatihan Keterampilan Penggunaan Media Mailing List Sebagai Media Belajar Bagi Siswa-Siswa di SMK Sari Buana Makassar. JATI EMAS (Jurnal Aplikasi Teknik dan Pengabdian Masyarakat), 1(2), 16-20.

Jorge, S. N. (2002, November). The economics of ICT: challenges and practical strategies of ICT use for women's economic empowerment. In UN Meeting on ICTs and their Impact on and Use as an Instrument for the Advancement and Empowerment of Women, Seoul, Korea (pp. 11-14).

Kabeer, N. (2012). Women's economic empowerment and inclusive growth: labour markets and enterprise development. International Development Research Centre, 44(10), 1-70.

Lahafi, F., Muchsin, A., Semaun, S., \& Rahim, Z. A. (2019). Development of Creative Industries Training Towards Sharia Economic Empowerment in Bilalangnge Community, Parepare City, South Sulawesi. Malaysian E Commerce Journal (MECJ), 3(2), 33-35.

Mengstie, B., \& Singh, A. (2020). Ethiopian Women Economic Empowerment Through Microfinance. Indian Journal of Finance and Banking, 4(2), 51-57.

Miles, M. B., \& Huberman, A. M. (1994). Qualitative data analysis: An expanded sourcebook. Sage

Sadji, Partoatmodjo. (2004). Masalah Kemiskinan dan Kompleksitas Penanggulangannya. Jakarta. Kementerian Koordinator bidang Kesejahteraan.

Saksono, H. (2012). Ekonomi Kreatif: Talenta Baru Pemicu Daya Saing Daerah. Jurnal Bina Praja: Journal of Home Affairs Governance, 4(2), 93-104. 
Septiyana, L., Nizaruddin, N., Rahmawati, N. I., Atma, S. R., Putri, A. S., \& Astuti, N. (2020). Pemberdayaan Ekonomi Kreatif Masyarakat Melalui Pengolahan Makanan Tradisional Kerupuk Dapros Di Desa Gunung Rejo. DEDIKASI: Jurnal Pengabdian Masyarakat, 2(1), 105-117.

Sugiyono. (2006). Metode Penelitian Pendidikan. Bandung : Alfabeta.

Utari, A. R. T., \& Riani, A. (2015). Analisis Kelayakan Usaha Ternak Sapi Potong pada Berbagai Skala Kepemilikan di Desa Samangki Kecamatan Simbang Kabupaten Maros [Skripsi]. Fakultas Peternakan. Universitas Hasanuddin. 